\title{
Um Balanço Bibliográfico e de Fontes da Estereoscopia
}

\section{Gavin Adams}

Programa de Pós-Graduação da ECA/USP

O balanço bibliográfico que se segue é uma reflexão acerca da organização de títulos que tratam da estereoscopia. Menos do que uma tentativa de listar todos os títulos disponíveis em uma bibliografia completa, a presente reflexão quer mapear os tipos principais de publicação de interesse estereoscópico encontrados no curso de pesquisa de doutorado. Ademais, o presente balanço quer oferecer uma meditação sobre algumas das particularidades e incidências da bibliografia encontrada, de modo a oferecer ao pesquisador da estereoscopia um guia inicial para seus trabalhos. Este fato explicará a organização um tanto idiossincrática com que este balanço bibliográfico está desenhado. A literatura acerca da estereoscopia apresenta-se dispersa por várias áreas, além da história da fotografia. As publicações específicas à estereoscopia são relativamente pouco numerosas, particularmente no que se refere aos textos de natureza analítica. Freqüentemente, a estereoscopia é mencionada apenas de passagem, sem maiores considerações a respeito de seu desenvolvimento. Tal é o caso no contexto da bibliografia consolidada da história da fotografia onde figura, via de regra, como um curiosa mas passageira modalidade da atividade fotográfica. Da mesma forma, na história do cinema, a estereoscopia em geral aparece ao lado de outros "brinquedos ópticos", no contexto da "pré-história" cinematográfica. A presença da estereoscopia no Brasil é particularmente mal documentada.

Na área mais ampla dos estudos da visualidade encontramos mais elementos para um acompanhamento cuidadoso do desenvolvimento dos processos dos quais a estereoscopia participou. Realizar pesquisa a partir de um instrumento só faz sentido se implicar redefinições em uma dada área, recolocando objetos e problemas importantes que vinham sendo ignorados ou preteridos, tendo como fruto o enriquecimento do conhecimento de processos que se cruzam no campo da visualidade. Assim sendo, valioso material acerca do assunto encontra-se 
disperso em publicações não obviamente relacionadas à fotografia, quais sejam, coleções ou publicações militares, médicas, cartográficas, astronômicas ou de agrimensura. Fazer sentido deste material díspar e disperso - utilizando-se dos estudos da visualidade - é o desafio que se apresenta ao pesquisador.

Ao reunir uma bibliografia acerca da história da estereoscopia, organizamos os títulos localizados em grupos temáticos, procurando estabelecer sua relevância para a pesquisa. Breves comentários procuram dar um contexto mínimo aos títulos listados. $\bigcirc$ viés deste balanço é francamente histórico, e predominam os textos em língua inglesa e portuguesa, o que não necessariamente representa o universo total da bibliografia estereoscópica, que também apresenta títulos importantes principalmente em francês, mas também em alemão. As publicações que fazem uso da imagem estereoscópica como recurso visual, mas que não tratam da história da estereoscopia, foram excluídas desta bibliografia. Da mesma forma, publicações que apresentam somente imagens, sem reflexão escrita sobre o tema não foram aqui listadas - exceto no caso do Brasil. Este tipo de publicação tipicamente apresenta coleções e acervos estereoscópicos. A razão pela qual encontram-se excluídos é o enorme volume de coleções norte-americanas, de interesse muito local. De qualquer forma, as publicações deste perfil integram o presente balanço, mas somente no contexto de outras diretrizes.

Problemas da pesquisa

que está em jogo na construção de um balanço bibliográfico é uma estratégia de abordagem teórica. A estereoscopia é um campo que exige, nos parece, o estudo de circuitos diversos: não só o da sua produção fotográfica lque se ramifica em diferentes áreas), mas também o de seu consumo. $\bigcirc$ caráter industrial e anônimo de grande parte de sua produção oitocentista exacerba a deficiência de abordagens biográficas, que na pesquisa histórica da fotografia oferece melhores resultados. Depois de um processo de difusão em massa, comparável ao cartão postal e ao carte-de-visite, a estereoscopia sofre, na virada do século XIX ao XX, um processo de migração para áreas distintas daquela que a consagrara, vale dizer, a do cartão estereoscópico publicado por um estúdio fotográfico e tipicamente visto na sala de visitas. Assim, esta bibliografia inclui textos das áreas militar, topográfica, médica e outras.

\section{Buscas}

A relativa invisibilidade da estereoscopia na bibliografia consolidada da fotografia tem como resultado o fato de que a simples digitação da palavrachave "estereoscopia", numa página de busca de acervo, pode não lograr resultados muito animadores - principalmente no caso de bibliotecas. Por outro lado, o oposto acontece na Internet, onde esta palavra-chave faz chegar milhares de títulos, numa verdadeira avalanche. Esta reflexão quer sintetizar um pouco da experiência acumulada no processo de garimpagem de títulos e de separação do joio do trigo, e se possível indicar algumas publicações-chave da estereoscopia. 
A Internet coloca-se cada vez mais como auxiliar do pesquisador. Encorajados pela falta de títulos específicos sobre a história da estereoscopia nas bibliotecas, procedemos à busca mais ou menos rotineira de informações na Internet. A estereoscopia figura de maneira bastante significativa dentro da rede, por vezes na forma de contribuições surpreendentes. Uma boa quantidade de informações foi assim localizada, na forma de fac-símiles de textos, artigos e ilustrações. Também é muito facilitada, na rede, a comunicação com outros autores. Não obstante, a busca bibliográfica na Internet não está a salvo de perigos. Dentre eles poderíamos mencionar o mais angustiante: a falta de "pedigree" da informação, isto é, detalhes de sua autoria e procedência. Muitas vezes a informação útil não se apresenta no formato acadêmico - livros são mencionados sem detalhes importantes como data ou editor - aleijando seu uso na pesquisa. A datação (e mesmo a autoria) de um artigo publicado na Internet também pode ser bastante difícil. Por outro lado, a permanência incerta do endereço por vezes inviabiliza o necessário retorno àquela informação. $E$, ainda mais freqüentemente, não se tem a mínima idéia de onde tentar a localização física de um tífulo mencionado. Para diminuir estes perigos, mas ainda assim fazer uso da Internet no levantamento bibliográfico, a seguinte política foi adotada: procuramos incluir nesta bibliografia somente o que julgamos essencial, alertando sempre o leitor sobre a procedência qualificada da informação, esperando que futuras buscas, deste autor ou de outrem, completem esta bibliografia.

\section{Recorte temporal}

Além do viés histórico, cabe também alertar o leitor a respeito do recorte temporal adotado para esta bibliografia. A data de invenção do estereoscópio é 1833. Em 1838, Charles Wheatstone apresentou à Real Sociedade 0 aparelho estereoscópico de sua invenção, a base de todos os aparelhos subseqüentes. Quando foi apresentado, o estereoscópio de Wheatstone fazia uso de desenhos, mas foi no formato fotográfico imediatamente subsequente que a estereoscopia experimentou franca expansão.

Este balanço bibliográfico, portanto, inicia-se no ano de 1833. Referências à "pré-história" da estereoscopia (Euclides, Leonardo, Helmoltz, etc.), ou melhor, investigações a respeito da binocularidade humana são citadas em muitos dos títulos aqui listados, em geral como preâmbulos aos textos principais. Informações mais detalhadas referentes às teorias da visão anteriores ao século XIX podem ser encontradas em histórias mais gerais destas teorias. Quanto à data de corte desta bibliografia, a posição é menos unívoca. A data escolhida como data de corte foi, um tanto experimentalmente, o ano de 1939. Assim procedemos porque a Segunda Guerra Mundial anuncia desenvolvimentos técnicos de caráter eletrônico que reposicionam a estereoscopia, afastando-a de maneira definitiva dos paradigmas ópticos do século XIX. Como conseqüência, alguns aspectos do desenvolvimento da estereoscopia não foram contemplados de maneira cuidadosa, tal como o formato Viewmaster. Igualmente, o cinema estereoscópico, que atingiu pico de produção nos anos 50, por não ser largamente documentado antes de 1939, não figura neste balanço de maneira consistente. Referências a estes desenvolvimentos, não obstante, por vezes encontram-se nos títulos listados (especialmente DARRAH, 1997; WING, 1996). 
1. Chroma-depth é um dos nomes pelos quais este processo é comercializado.

2. Outros termos associados ao par de fotografias estereoscópicas são: estereogramas, estereofotografias, estereoscopias, cartões estereoscópicos, estereografias e vistas estereoscópicas. Estereoscópio designa o visor onde os estereogramas são colocados e examinados.Ainda outra advertência acerca da confusão reina ao redor da palavra Stereopticon. Refere-se a um tipo de lanterna mágica não-estereoscópica, mas confusamente houve quem usasse Stereopticon para designar o estereoscópio (como o Handmade Stereopticon Slide de Duchamp (In KRAUSS, 1994,p. 134). Da mesma forma, o termo panorama pode incluir um tipo de aparato de vistas estereoscópicas, como o Kaiser-Panorama (WING, 1996, p. 232). Sua acepção mais universal refere-se àquele tipo de edifício circular que abrigava uma grande tela, de 360 graus, onde é pintada a vista de uma cidade ou batalha, como descrito em Dubbini (1997, p. 75-76).
Alerta semântico ao pesquisador

A primeira advertência ao pesquisador da estereoscopia está relacionada aos termos em uso na literatura estereoscópica. $\bigcirc$ termo "3-D" (também grafado 3D ou 3-d) ou "tridimensional" é o conceito de alcance mais geral e amplo, abarcando todas as técnicas de produção do "efeito de relevo". Isto quer dizer que o termo estereoscopia não é idêntico a 3-D. A estereoscopia envolve necessariamente a binocularidade e a conseqüente síntese de duas imagens díspares chamada stereopsis. Outras técnicas estereoscópicas incluem o anaglifo (também anáglifo ou anaglífico), o "térmico" I, o Pulfrich e o Olho Mágico (Random Dot Pattern) $)^{2}$.

Breve relato da história da estereoscopia

A estereoscopia acompanha todas as fases de desenvolvimento da fotografia, e de fato a precede. Longe de ser uma curiosidade acessória, a ela devemos total ou parcialmente muitas das conquistas e inserções tecnológicas e de uso social da fotografia: fotografia instantânea, cobertura de eventos, forense, pornográfica, etnográfica, etc.

A estereoscopia surgiu - como fenômeno de massa - em 1851. Apresentada ao público por ocasião da Exposição Universal de Londres desse ano, por David Brewster, revelou-se um sucesso imediato, conquistando a pronta adesão da rainha Vitória. Venderam-se mais de mil estereoscópios no Reino Unido somente nesse ano. Em todo o mundo as vistas estereoscópicas fizeram enorme sucesso.

No ano de 1862, a London Stereoscopic Co. vendeu, na Segunda Exposição Universal de Londres, mais de um milhão de cartões fotográficos estereoscópicos, fazendo jus a seu slogan de "nenhuma residência sem o estereoscópio". Este sistema de cópias fotográficas sobre papel, montadas sobre cartão e vistas através de visores, foi desenvolvido por Oliver Wendel Holmes, um dos maiores adeptos da estereoscopia.

Holmes pregava a formação de um "arquivo do presente", uma documentação estereoscópica extensiva das paisagens geográficas e humanas do mundo, incluindo o conflito humano da guerra. Fotógrafos dos estúdios percorriam o mundo, acumulando vasto número de imagens em inúmeras coleções. A cidade do Rio de Janeiro fazia parte do circuito "exótico" de vistas, tendo sido documentada no formato estereoscópico por, dentre outros, fotógrafos da Amateur Photographic Society e da Anthony Co. Coleções de títulos como "O mundo no estereoscópio" e "Viagem à Terra Santa", e o ambicioso "Orbis Terrarum" prometiam "um panorama geral do mundo" em substituição a uma viagem real: "à lareira temos a vantagem de poder examiná-las [as vistas] - sem o desconforto" da experiência real. Temas bíblicos e históricos também eram contemplados, assim como "Diableries", historietas, guerras, coroações, execuções públicas, extensa produção pornográfica e aplicação científica. 
Da popularidade mundial do novo formato participou também o Brasil, e não exclusivamente pelo interesse de D. Pedro II, adepto, mecenas e colecionador fotográfico. Fotógrafos como V. Frond, A. Stahl, Leuzinger, Renouleau, Marc Ferrez e R. H. Klumb (este com ampla produção) produziram estereofotografias no século XIX, além de Militão Augusto de Azevedo.

De fato, a abundante produção fotográfica brasileira parece ter incluído, a exemplo da atividade profissional européia, o uso possivelmente corriqueiro da estereoscopia como serviço normal de um profissional de certo porte. Há várias notícias de fotógrafos e casas editoras comercializando produtos próprios ou de terceiros, ao correr de amplo período - 1872 a $1905^{3}$.

A partir de 1870 a estereoscopia entrou em declínio na Europa, experimentando renovado interesse a partir de $1880 \mathrm{com}$ grandes corporações norte-americanas, alcançando seu ponto máximo de expansão global na virada do século XIX ao XX. Neste ponto, a estereoscopia encontrava-se consolidada em várias áreas do conhecimento humano, e atingia também o mercado do fotógrafo amador. A Primeira Guerra Mundial mobilizou a estereoscopia em vários níveis: o da reportagem (das equipes das grandes corporações estereoscópicas), o privado lo soldado ou oficial amador registrando estereoscopicamente a realidade das trincheiras), o médico (registro de mutilações) e o militar (os primeiros passos da aerofotogrametria).

\section{A Bibliografia Comentada}

\section{Títulos básicos}

Este balanço bibliográfico inicia-se com dois títulos que se recomendam como textos de referência, pois facilitam a tarefa da delimitação temporal e geográfica geral da estereoscopia, ao oferecer um panorama amplo da produção estereoscópica no seu formato consagrado - os cartões estereoscópicos. Pela abrangência e riqueza do material visual que encerram, Darrah (1997) e Wing (1996) merecem destaque, ainda que com as reservas que se mencionam a seguir.

Talvez o mais citado livro na bibliografia estereoscópica é o opus magnum de W. C. Darrah, The World of Stereographs. Publicado pela primeira vez em 1977, este livro conheceu várias reedições que se estenderam até 1997. Os alcances temporal e geográfico deste livro são admiráveis, assim como a quantidade colossal de material que este autor coleta e organiza - centenas de estereogramas e uma lista de outras centenas de estereógrafos em todo o mundo, inclusive o Brasil ${ }^{4}$. Detalhes técnicos da fabricação de cartões são examinados de modo a servir de guia para a datação de peças. Trata-se de um livro essencial à pesquisa estereoscópica, um admirável panorama tanto da história e desenvolvimento da estereoscopia quanto da variedade e alcance das imagens estereoscópicas. $\bigcirc$ livro está dividido em quatro partes, mais apêndice, bibliografia e índice de temas. A primeira parte, "Histórica", traz uma periodização e caracteriza cada época do desenvolvimento da fotografia estereoscópica. A segunda parte é intitulada "Geográfica - vistas regionais". A terceira parte apresenta um guia temático das
3. O Almanak de Campinas de 1872: "Vende-se álbuns, quadros, vistas stereoscopicas etc., por preços baratíssimos." O Almanak Laemmert para 1903 traz o anúncio de uma nova versão do estereoscópio "que acaba de ser inventado. Substitue, de modo maravilhoso, o antigo stereoscópio e pode ser trazido na algibeira". Anunciam-se também coleções estereoscópicas à venda: "Hespanha, pais das maravilhas","Volta ao Mundo", além de "Cousas Picantes" e "Mysterios do Harém". No mesmo almanaque, desta vez do ano de 1905 , encontramos um anúncio da Photographia União: "bonita coleção de vistas estereoscópicas, [além de São Paulo] também de Santos e arredores, todos tirados a capricho pelo photographo Marques Pereira" (também KOSSOY, 2000, p. 59).

4. R. H. Klumb, R. H. Fuhrman, G. Leuzinger, Henschel e Benque. O texto contém certos erros factuais, como a grafia de D. João VI (Dom Jogo) e a confusão entre Pedro I e Pedro II, apontados como a mesma pessoa. 
5. Estão listados Benque, Henschel e Benque, Marc Ferrez, R. H. Fuhrman, Gutzlaff, R. H. Klumb, Leuzinger, Lopes, Photographia Brasileira. imagens estereoscópicas, "arranjadas à maneira enciclopédica". A quarta parte compreende duas listas de estereógrafos americanos, uma arranjada por ordem alfabética e a outra por data. $\bigcirc$ Apêndice demonstra um cálculo aproximado do número de estereógrafos americanos, além de Bibliografia e Índice. Não obstante sua abrangência, The World of Stereographs limita-se a ser um guia descritivo, ainda que bastante completo e ricamente ilustrado. Se é um título essencial à pesquisa, o é como um guia ou mapa geral, pois o pesquisador não encontrará análise histórica mais sofisticada do que a caracterização de uma linha do tempo comentada.

Onde Darrah apresenta cartões estereoscópicos, Wing se atém aos visores estereoscópicos. Ricamente ilustrado, Stereoscopes: the First Hundred Years traz belos exemplares dos mais variados estereoscópios de todos os períodos e formatos: os consagrados aparelhos portáteis de mão (Brewster e Holmes-Bates), de mesa, de bolso, dobráveis, livros estereoscópios, tele-estereoscópios, estereoscópios de múltiplas vistas (com mecanismo de troca), medalhões estereoscópicos, o sistema Verascope, estereoscópios militares, além dos estereografoscópios. O livro mostra também numerosas reproduções de material publicitário e patentes dos séculos XIX e XX. A rivalidade entre Brewster e Wheatstone é bem documentada, e a evolução e diversificação dos diferentes tipos de estereoscópios são acompanhadas passo a passo. $\bigcirc$ livro é dividido em 10 capítulos e três apêndices, bibliografia e glossário de termos franceses. Os capítulos são intitulados: Inglaterra e França, 1832-1 855; Inglaterra e o Continente, 18561890; Estados Unidos, 1854-1860; Visores-Caixa de daguerreótipos; $O$ visor Holmes-Bates; Estados Unidos, 1861-1890; Estereografoscópios; Estados Unidos, 1890-1930; O Continente, 1890-1940; Final. Os apêndices: o catálogo geral Bernhard Wachtl de 1903; Patentes americanas de 1853-1902; A primeira patente estereoscópica. O livro de P. Wing apóia-se no estudo de patentes e de aspectos técnicos dos visores estereoscópicos, e tem um viés um tanto colecionista. Como um guia para a identificação e datação de aparelhos, seu valor é inestimável. Não obstante, a maior parte do texto é dedicada à descrição física dos estereoscópios, sem maiores considerações pelos movimentos da história ou pelas conseqüências culturais de diferentes tipos de modalidades estereoscópicas. A exemplo de Darrah (1997), Stereoscopes: the First Hundred Years é útil como guia, mas não trata da inserção da estereoscopia em desenvolvimentos mais amplos da visualidade.

Treadwell e Darrah (1994) trazem, por sua vez, uma lista de mais de 13 mil fotógrafos estereoscopistas, categorizados por país ou estado, além de bibliografia. A obra, em dois volumes, traz mais nomes americanos do que aqueles estrangeiros aos Estados Unidos, inclusive o Brasil ${ }^{5}$. O valioso trabalho realizado pelos autores deve ser avaliado à sombra do método adotado na seleção de nomes, isto é, a cada nome não corresponde necessariamente uma imagem estereoscópica examinada pelos autores. Os nomes foram colhidos de livros, panfletos e outras fontes (conforme informam na p. 1).

\section{A estereoscopia e a literatura do séc. XIX}

Poucos grandes autores do século XIX discorreram sobre a estereoscopia 
Baudelaire, Marcel Proust, Kafka, W. Benjamin e Eisenstein comentaram a estereoscopia especificamente ${ }^{6}$, mas a regra é a pouca ocorrência de textos de peso, pelo menos até o início do séc. XX. O que este balanço oferece em seguida ao pesquisador, por outro lado, são os textos que poderíamos chamar de fundadores. Estas três obras formam um cânon de certa forma estável e consensual na literatura estereoscópica, ainda que tenham por autores estrelas relativamente menores no firmamento das letras oitocentistas. Estes textos são freqüentemente citados em todas as épocas subseqüentes nos mais diversos contextos, e foram cruciais para a difusão da estereoscopia. $\bigcirc$ contexto de produção das três obras é típico da investigação científica do século XIX: seus autores têm o perfil do gentleman amateur, que é o homem de posses que dedica seu tempo e energia à investigação científica, geralmente em várias áreas. $\bigcirc$ estudo da óptica e da fisiologia do olho humano já vinha ocupando, a partir da virada do século XVIII ao XIX, as mentes dos cientistas e diletantes da Europa. $\bigcirc$ estereoscópio resulta dessas investigações. Os três textos "fundadores" trazem: a descrição do primeiro estereoscópio por seu inventor (WHEATSTONE, 1838); a difusão do estereoscópio, que passa de aparelho científico a objeto de consumo popular (BREWSTER, 1856); e a estereoscopia no contexto do consumo de imagens no século XIX (HOLMES, 1864).

A invenção do primeiro aparato estereoscópico é obra de Sir Charles Wheatstone, que apresentou seu invento à Real Sociedade em 21 de junho de 1838, num texto intitulado Contributions to the Physiology of Vision. Part the First. On some remarkable, and hitherto unobserved, Phenomena of Binocular Vision. Seu estereoscópio é a base de todos os aparelhos estereoscópicos subseqüentes. Este texto confere uma legitimidade científica que foi muitas vezes mobilizada em discursos posteriores de proponentes da estereoscopia. $\bigcirc$ texto inicia-se com considerações a respeito da binocularidade, examinando as diferentes teorias acerca da visão humana correntes na época, procurando provar que as percepções de relevo e profundidade são derivadas da binocularidade. Em seguida, apresenta o estereoscópio e seu funcionamento. Discorre a respeito das diferentes imagens que examina com seu aparelho: contornos de um cubo, um cone, uma pirâmide, várias curvas e retas las imagens são desenhos, já que a fotografia não fora ainda inventada). Nota, em seguida, o fenômeno da pseudoestereoscopia, que é o efeito obtido quando ao olho direito se apresenta a imagem da esquerda, e vice-versa.

Sir David Brewster, por sua vez, foi um dos principais difusores da estereoscopia. Sua rivalidade com Wheastone foi acirrada e, mais do que seu rival, ele perseguiu a comercialização e popularização do estereoscópio, além de procurar trazer para si o manto do reconhecimento pela proposição da estereoscopia - e para tal escreveu The Stereoscope; it's History, Theory and Construction. Cientista versátil, redigiu numerosos textos em diversas áreas, especialmente óptica. Inventou também o caleidoscópio em 1816, que obteve enorme sucesso junto ao público de todas as classes. Apesar de Wheatstone ter pensado e perseguido a idéia do uso do recém-inventado daguerreótipo, foi Brewster quem aperfeiçoou o aparelho, inventando seu modelo portátil com lentes de aumento (estereoscópio de Brewster ou estereoscópio lenticular), que foi a forma em que primeiro se popularizou e famosamente chamou a atenção da rainha Vitória na Exposição Universal de Londres de 1851. Seu influente livro condensa a experiência estereoscópica até então, percorrendo aspectos da tomada
6. Baudelaire:"An avenging God has heard the prayers of the multitude. Daguerre was his messiah... It was not long before thousands of pairs of greedy eyes were glued to the peepholes of the stereosocpe, as though they were sky-lights of the infinite"(Baudelaire - "The Modern Public and Photography", apud JAY, 1993,p. 138). Proust - "The stereoscope rather than the single photograph was the key to a liberating visual experience for Proust" (JAY, 1993, p. 184). Kafka descreve sua experiência do Kaiser-Panorama, onde imagens estereoscópicas se sucedem continuamente (DUBBINI, 2002, p. 206). Benjamin descreve o lado pedagógico de seu trabalho:" "to educate the imagecreating medium within us to see dimensionally, stereoscopically, into the depths of historical shade" (carta deW.Benjamin para Adorno, 9 de setembro 1938, apud BUCK-MORSS, 1990, p. 292) Eisenstein: "Binocularity is the existence of two viewpoints that enable na object to be seen in relief. The same principle underlies the multiviewpoint, sequential nature of montage" ("Towards a Theory of Montage" apud DUBBINI, 2002, p. 204). 
de imagens estereoscópicas, detalhes da construção de sua versão do estereoscópio, e aspectos da experiência da mirada estereoscópica. Sugere, à guisa de chiste, que é possível realizar imagens estereoscópicas de fantasmas, em alusão à então corrente moda da "fotografia de espírito". Brewster também relata sua versão da história da estereoscopia, procurando desabonar a prioridade de Wheatstone. Em seu texto, por exemplo, apresenta o notório "desenho estereoscópico" de Jacopo Chimenti, artista florentino do século XVI, como prova da antigüidade da estereoscopia. Hoje, o consenso é que não se trata de um desenho estereoscópico, e mesmo na época, esta proposição foi fortemente contestada (entre outros, por Helmholtz). Além disso, afirma que os princípios por trás da imagem estereoscópica foram desenvolvidos por Euclides na Grécia antiga, o que não foi nem é aceito.

norte-americano Oliver Wendell Holmes foi um dos mais entusiasmados difusores da estereoscopia. Escreveu três influentes textos sobre o tema no periódico americano Atlantic Monthly (lançado em 1857), do qual era colaborador. Esses três textos (The Stereoscope and the Stereograph, Sun-painting and Sun Sculpture e The Doings of the Sunbeam) foram depois reunidos e editados em um só volume, Soundings from the Atlantic (1861). Nele, Holmes discorre sobre a natureza da estereoscopia, propõe a mirada estereoscópica como uma espécie de viagem virtual, e cunha várias frases e formula muitas das idéias que foram depois amplamente mobilizadas: o transporte no tempo e espaço, acesso privilegiado à realidade visual, aspectos educacionais e edificadores da mirada estereoscópica (Underwood \& Underwood, poderosa corporação da indústria estereoscópica da passagem do século XIX ao XX, incorporou vários trechos do texto de Holmes em sua propaganda e em seu material de treinamento de vendedores. Chegou a publicar Soundings from the Atlantic, dirigido tanto ao público consumidor como a seus funcionários). Holmes escreve do ponto de vista do consumidor de imagens estereoscópicas, e guia o leitor em uma "viagem estereoscópica" através de sua coleção particular de estereogramas. Se seu estilo soa um tanto verborrágico para o leitor moderno, é surpreendente como certas idéias acerca da estereoscopia (e da realidade virtual) tenham sido formuladas tão cedo. Um exemplo recorrente no discurso de Holmes e presente em tantos outros discursos acerca da estereoscopia é o renitente adventismo. A estereoscopia parece sempre estar prestes a ser reconhecida como a maravilha da época e largamente utilizada nas empresas humanas mais urgentes. É quase um formato à espera de aplicação: reconhece-se a singularidade da imagem estereoscópica, mas parece que há sempre certa dificuldade na sua aplicação imediata. Brunet (2001) traduz para o francês e apresenta parte do texto Sun Painting and Sunsculpture - with a stereoscopic trip across the Atlantic, enquanto Treadwell (2000) traz fac-símile completo de Soundings from the Atlantic. Wade (1983) expõe os textos de Wheatstone e Brewster.

\section{A estereoscopia no campo da visualidade}

livro de Jonathan Crary, Techniques of the Observer (1990), é provavelmente a obra mais significativa da literatura estereoscópica. Um marco na literatura da visualidade, o texto de Crary realinha consensos em relação ao 
desenvolvimento da fotografia e da modernidade, atribuindo ao estereoscópio importância-pivô na compreensão dos processos de transformação lançados pelo capitalismo no século XIX. $\bigcirc$ autor apresenta o estereoscópio como metáfora visual para o século XIX, em oposição à camera obscura, que sintetiza o regime visual do século XVIII. A camera obscura, escreve o autor, mantém uma relação desimpedida entre o interno e o externo, isto é, o observador e o mundo real, estabelecendo uma relação de correspondência simbolizada pelo raio de luz que, sem barreiras, penetra pelo orifício e vai imprimir-se no lado de dentro da camera obscura. A qualquer movimento no espaço externo corresponde uma mudança na imagem projetada internamente. No estereoscópio, ao contrário, esta correspondência com o real não se aplica, particularmente quando faz uso de desenhos. $\bigcirc$ real, mesmo se fotografado para o estereoscópio, manifesta-se como uma imagem sintética operada a partir das diferenças entre duas imagens. As novas teorias da visão que não dependiam do real, desenvolvidas na virada do século XVIII ao XIX, solaparam a noção de realismo que aparentemente operou sem nenhuma perturbação no século XIX - e de toda forma a modernização operada no século XIX não dependeu deste realismo. $\bigcirc$ estereoscópio seria resultado desta pesquisa acerca da fisiologia ocular e dos "defeitos da visão": retenção retinal, binocularidade, visão periférica. Este realinhamento do observador coincide com uma ruptura com modelos clássicos de visão.

Um processo de reorganização da visão, portanto, estava em pleno desenvolvimento na primeira metade do século XIX, produzindo um novo tipo de observador, que se percebe paulatinamente obrigado a funcionar nos espaços urbanos disjuntos, sofrer os efeitos dos deslocamentos do trem, da telegrafia e da torrente de informação visual. Esta reorganização é inseparável da reorganização do conhecimento e das práticas sociais que modificaram a vida humana, modernizando-a. Esta afirmação contraria poderoso consenso na história da arte e da fotografia, que até então procurava nas representações da arte os sintomas do realinhamento do olhar moderno, que só haveria de se consolidar no final do século XIX com o Impressionismo. Crary vale-se das análises de Foucault, para quem a modernidade do século XIX é inseparável da maneira com que mecanismos dispersos de poder coincidem com novos modelos de subjetividade. Apesar de ter examinado instituições disciplinares como prisões, escolas e as militares, Foucault também descreve o papel das recentemente constituídas ciências humanas em regular e modificar o comportamento de indivíduos (CRARY, 1990, p. 15).

Crary não está a salvo de críticas. Richardson, em seu artigo intitulado Double Vision is but Perfect Vision (1999), acentua reservas ao seu livro, afirmando que o caráter fotográfico é inseparável da experiência estereoscópica do século XIX. Isto significaria que a ruptura proposta por Crary é menos radical ou mesmo inexistente, pois se a estereoscopia foi um fenômeno eminentemente fotográfico, e esta se coloca mais confortavelmente dentro da tradição perspéctica renascentista, há continuidade e não ruptura na formação do observador moderno.

Batchen, por sua vez, afirma em seu artigo Enslaved sovereign: on Jonathan Crary, techniques of the observer (1991), que o estereoscópio não sinaliza a desencarnação (disembodiment) do olhar defendida por Crary, mas sim que promove o movimento entre duas mobilidades, simultaneamente prendendo o olhar (imobilizado e isolado pelo visor) e liberando-o no espaço visual onde pode moverse entre os diferentes planos. Também é questionada a separação das experiências fotográfica e estereoscópica, apontando que foi a fotografia e não a estereoscopia que acabou por se tornar dominante. 
Rosalind Krauss, em seu livro The Optical Unconscious (1994), fala do estereoscópio no contexto das experiências ópticas de Marcel Duchamp, que experimentou com a estereoscopia, e da sensibilidade visual dos surrealistas franceses. A autora escreve que os movimentos do olhar e do corpo são feitos sinônimos na experiência estereoscópica, quando o olho recoloca o foco a cada plano.

\section{A estereoscopia nos títulos gerais sobre a história da fotografia}

Como já afirmamos acima, as histórias da fotografia tendem a mencionar a estereoscopia de passagem. Gernsheim (1988) dedica um breve capítulo ao assunto. Seu relato sobre seu desenvolvimento não acrescenta muito àquele de Darrah (1 997), mas traz informação nova ao afirmar que foi a câmera estereoscópica que introduziu o instantâneo na fotografia, devido à distância focal pequena que apresentava (GERNSHEIM, 1988, p. 69). Scharf (1974, p. 352), em seu título Art \& Photography, não the dedica um capítulo à parte, mas afirma que o ponto de vista elevado (high vantage point) de certas pinturas impressionistas coincidem com aquele apresentado por vistas estereoscópicas específicas de Paris, e que o enquadramento que "corta" pessoas ou objetos mais ou menos aleatoriamente é recorrente nas referidas vistas estereoscópicas. Newhall (1982, p. 1 15), no livro History of Photography, destina algumas páginas à estereoscopia, escrevendo também sobre o caráter instantâneo da fotografia estereoscópica. Em History of Photography são abordados vários aspectos de sua história e produção, entre eles a criação da radiografia estereoscópica em 1896 (EDER, 1945, p. 381-385).

A exposição Paris em 3-D: da estereoscopia à realidade virtual $1850-$ 2000, no Musée Carnavalet, Paris, de 4 de outubro a 31 de dezembro de 2000, foi acompanhada da publicação de um catálogo (TABRUN; TIMBY, 2000). A exposição e publicação têm por tema a cidade de Paris vista através da estereoscopia. Belíssimas imagens acompanham os textos de autoria dos editores e incluem Michel Tournier, Michel Frizot, Hubert Damisch, Denis Pellerin, Jacques Périn e Anne-Marie Duguet.

Córdova [s.d.] estuda a atividade estereoscópica no México entre 1850 e 1920. $\bigcirc$ autor identifica não só os indivíduos e estúdios produtores das imagens estereoscópicas, como também seus circuitos de consumo, além de contexto dentro do qual estas eram circuladas. A produção estereoscópica mexicana parece muito expressiva em termos de quantidade. Nesse artigo, o autor elenca 33 fotógrafos ativos na produção estereoscópica, responsáveis por um número bastante grande de imagens (na casa dos milhares). Por um lado, é alentador que - México tenha produção estereoscópica expressiva, confirmando-se a presença deste tipo de registro fotográfico também na América do Sul. Por outro lado, o contraste com a produção estereoscópica brasileira conhecida é tal que este pesquisador se pergunta se é possível uma comparação com o Brasil, e em caso afirmativo, por que este país não a conservou em proporções semelhantes.

Vasquez traz menção à estereoscopia no contexto do envolvimento de

D. Pedro II com a fotografia, em seu livro Dom Pedro II e a Fotografia no Brasil (1988). $\bigcirc$ patronato que o imperador exerceu sobre Revert H Klumb teve como 
frutos várias vistas estereoscópicas da cidade do Rio de Janeiro e de Petrópolis, executadas pelo fotógrafo alemão. Que o próprio imperador conhecesse a estereoscopia é confirmado por saborosa anotação de 1856 em seu diário, presumivelmente depois de uma visita a um estabelecimento fotográfico: "Notei fotografias obscenas para estereoscópio, devia ao menos tirá-las do mostrador" (VASQUEZ, 1988, p. 18). Aqui, uma espécie de "lado B" da modernidade no Brasil: cruzamentos dos vetores da pornografia, da estereoscopia e do poder. Ferrez (1985, p. 60) faz menção à estereoscopia ao reproduzir um anúncio da Casa Leuzinger, onde figura uma oferta de aparelho estereoscópico em seu livro A fotografia no Brasil: 1840-1900. Kossoy (2002, p. 59), na obra Dicionário histórico de fotógrafos e do ofício fotográfico no Brasil (1840-1910), e informa que "são constantes os anúncios sobre a venda deste produto visual em quase todas as províncias do país".

A mais notável exceção nacional à regra do confinamento da estereoscopia ao rodapé é o livro de J. I. Parente (1999, p. 16-18), A estereoscopia no Brasil (1999). Este livro traz notável conjunto de imagens estereoscópicas de várias procedências. As pioneiras fotografias de R. Klumb são amplamente representadas, assim como as de Guilherme Santos em suas imagens publicadas pela companhia Cigarros Veado. Óculos estereoscópicos acompanham a obra. Parente propõe uma periodização para o desenvolvimento da estereoscopia no Brasil: Precursores 1855-1895, Figurinhas e Cartões 1895-1915, e Era do Verascope 1910 -1958. São apresentadas ainda referências bibliográficas e uma lista de instituições pesquisadas e de endereços na Internet. $\bigcirc$ valor da obra deriva de sua originalidade e das belas imagens que difunde, pois o texto que as acompanha não é de análise histórica muito profunda, limitando-se a traçar uma linha do tempo e ambientar o leitor às épocas descritas.

Turazzi (1995), por sua vez, oferece horizontes mais amplos para a pesquisa estereoscópica, em seu livro Poses e Trejeitos: a fotografia e as exposições na era do espetáculo. A autora usa a estereoscopia como metáfora para o projeto de construção de uma idéia de Brasil, apontando para a mobilização da fotografia por D. Pedro II dentro de "um processo mais amplo de construção e afirmação de uma 'identidade brasileira'". A fotografia era identificada "no contexto do século XIX, com certa leitura da 'historia nacional' que, de um lado, constatava e 'reproduzia fielmente' o presente, legitimando-o e, de outro, elaborava imagens 'capazes de viabilizar num futuro não-definido a realização plena de sua identidade" (1 995, p. 109). A autora examina a presença da fotografia no circuito das exposições que "faziam parte deste conjunto de projetos e realizações que respondiam aos interesses da política no Estado imperial, na medida em que internamente promoviam uma integração do território sob a tutela da Corte e, externamente, ajudavam a atrair 'capitais, braços e inteligência' da Europa" (1995, p. 107). A própria estereoscopia é citada como parte deste processo, por exemplo, como item no catálogo da Exposição de 1866 (1995, p. 125), ou ainda no relatório da Exposição Provincial de 1866: "Atualmente são conhecidos na província todos os sistemas fotográficos" (1995, p. 109).

Turazzi (1997) explora ainda, em sua tese de doutorado intitulada Artes do ofício: fotografia e memória da engenharia no século XIX, a cultura fotográfica na formação e atuação do engenheiro no século XIX, assim como a produção fotográfica documentária e de memorização da obra de engenharia, investigando a interessante convergência com o projeto nacional de melhorias de 
7." [...] It is then rigorously true that the surprise and admiration excited by the stereoscope, does not arise from the truth of the picture which it presents, but from the strong exageration of perspective and relief which it exhibits. It is very true that no art of the draughstman or painter could produce any such effects, but it is also equally true that no such effects could be produced by the objects themselves" (LARDNER, 1856, p. 144).

8. O título trata do uso da fotografia - incluindo a estereoscópica - no contexto do reconhecimento militar. Esta obra era parte da biblioteca de D. Pedro II e traz dedicatória do autor ao monarca.
D. Pedro II. A estereoscopia é, como demonstra a autora, elemento desta construção da imagem de um Brasil em desenvolvimento. As duas obras da autora balizam de maneira poderosa o campo de atuação da imagem e seu uso no Brasil, mobilizando ampla gama de documentos e discursos.

\section{Referências à estereoscopia em outras áreas do conhecimento}

A popularização do estereoscópio gerou toda uma onda de textos onde se discutem aspectos ligados à estereoscopia e à binocularidade (INGLEBY, 1853; LONIE, 1856; MOIGNO, 1852; MONCKHOVEN, 1863; SMEE, 1854), tanto textos científicos quanto de difusão popular. Lardner (1856), em seu periódico de ciência popular, The Museum of Science and Art, destaca-se por se colocar contra a maioria dos escritos ao redor da estereoscopia, que são quase sempre laudatórios? . Em 1860, um médico descreve o uso que fizera de um binóculo de ópera, acoplando a ele um visor estereoscópico, e voltando-os para uma pintura de paisagem, tornando-a mais "natural" (JONES, 1860, p. 29-30). O mesmo par de óculos modificado é voltado para uma paisagem natural, fazendo desta um cenário artificial - um "palco". Moitessier (1866) discute o uso da estereoscopia na microscopia. Já Piazzi-Smyth (1856) escreve a respeito de suas experiências como astrônomo e suas observações astronômicas em Tenerife, quando era Astronomer Royal for Scotland. Este livro contém as primeiras imagens estereoscópicas a serem publicadas, atendendo a um apelo de Brewster (GERNSHEIM, 1988, p. 67).

A medicina fez largo uso da estereoscopia e incorporou o método em várias áreas de sua especialização, como na radiografia. A medicina parece ter encontrado formatos estáveis de uso estereoscópico, pouco mudando ao correr das décadas (ao contrário da área militar ou do cinema). Um desses formatos consagrados é o atlas estereoscópico. O Edinburgh Stereoscopic Atlas of Anatomy conheceu sucessivas reedições, de 1900 até o fim do século XX ICUNNINGHAM, 1900). Gravy (1907) traz soberbas imagens do labirinto auricular de várias espécies animais.

O uso da estereoscopia no campo militar é desigual e de difícil acompanhamento. É importante separar a fotografia sobre a guerra e a fotografia de uso militar. No primeiro grupo encontram-se as famosas estereoscopias da Guerra Americana de Secessão, de autoria do fotógrafo Brady e sua equipe (ZELLER, 1997). O segundo grupo é o que apresenta mais problemas ao pesquisador. Apesar do uso militar da fotografia estereoscópica ter sido proposto já em 1862 por Disdéri (segundo KIESLING, 1896, p. 7), e Jouart (1 866) descrever a estereoscopia no contexto de seu uso pelas forças armadas francesas em seu livro Application de la Photographie aux levées militaires ${ }^{8}$, a utilização efetiva da estereoscopia pelas forças armadas demorou a se consolidar, e somente com o advento do aeroplano e com o franco desenvolvimento da fotogrametria é que foi possível configurar um campo estereoscópico de representação do campo de batalha. Exemplo de uso consolidado da estereoscopia na interpretação de fotografias aéreas está em Department of the Army (1960). Paul Virilio (1989) é quem melhor apresenta o desenvolvimento do engajamento visual das forças militares no campo de batalha e, a despeito de elaborar sobre o caráter 
cinematográfico da guerra na era industrial, constitui um terreno crítico onde é possível identificar operações estereoscópicas. Westell (1909) dedica seu livro Nature Stalking for Boys: Through the Field Glass, Stereoscope and Camera aos adeptos do escotismo, e seu interesse para o pesquisador deriva da mobilização de operações visuais (inclusive estereoscópicas) em termos flagrantemente militares, sugerindo a mobilização de uma operação visual universalizada no âmbito civil (a mirada estereoscópica) para fins militares. Em The Denigration of Vision in Twentieth-Century French Thought, Jay (1993) relata a influência das novas mobilizações do olhar pela Primeira Guerra Mundial nos artistas das vanguardas.

relacionamento da estereoscopia com o cinema é dos mais interessantes. Projeções estereoscópicas de Lanterna Mágica já eram mencionadas em textos dos anos 1850 (LONIE, 1856, p. 59; SMEE, 1854, p. 93). Hayes afirma que existe uma versão estereoscópica do famoso filme Trem entrando na Estação de Ciotat, produzido pelos irmãos Lumiére (1989, p. 3). Gosser (1977) investiga quanto da tecnologia desenvolvida para estereoscópios foi utilizada na construção das primeiras câmeras e projetores cinematográficos. Este autor menciona as tentativas de E. Muybridge e J. Marey na direção da cronofotografia estereoscópica (GOSSER, 1977, p. 167-170). Spotiswoode e Spotiswoode estudam problemas da transmissão (grosso modo, a projeção) estereoscópica do cinema. Suas reflexões iniciais (1-6) tratam dos problemas enfrentados nos primeiros anos do cinema estereoscópico e lançam luz sobre aspectos do encontro entre cinema e estereoscopia. Richard (1982, p. 38-39) traz duas páginas descrevendo os dois filmes estereoscópicos realizados pelo animador escocês Norman McLaren em 1950-51.

As corporações estereoscópicas e suas publicações

As grandes companhias estereoscópicas foram responsáveis pela produção da maior parte das imagens estereoscópicas dos anos entre 1885 e 1935, particularmente nos Estados Unidos. Empresas como Kilburn, H. C. White, Keystone View Company, E \& H.T. Anthony \& Co, e Underwood \& Underwood dominaram o mercado estereoscópico. $\bigcirc$ catálogo de algumas delas chegou a ultrapassar a casa das 10 mil imagens. $\bigcirc$ amplo material publicado por essas empresas, entre catálogos, textos de difusão e propagandas, ajudam muito na compreensão do mercado estereoscópico da virada do século XIX ao XX. Os cartões estereoscópicos destas companhias eram vendidos agrupados em coleções temáticas, freqüentemente acompanhadas de folheto explicativo do sistema ou trazendo informação acerca das imagens dos cartões. Há uma vasta quantidade de folhetos e catálogos que sobreviveram até nossos dias. É difícil, porém, obter detalhes completos e seguros sobre os títulos à venda em todo o período de atividade comercial de uma empresa. Fiéis ao que viam como sua missão educadora, em seu material gráfico de propaganda essas corporações estereoscópicas não poupavam espaço na elaboração de considerações laudatórias sobre o seu produto. No caso da Underwood \& Underwood, um número limitado de idéias era repetido de várias maneiras e em vários formatos. Assim, publicações como a de Osborne (1 909), intitulada The Stereograph and the Stereoscope With Special Maps and Books forming a Travel System and What 
They Mean for Individual Development, with their promise for the Spread of Civilization, e a de Keystone (1872), The World in the Stereocope, condensam em suas páginas argumentos sobre os pontos principais de todo o material publicitário. Osborne (1 904) traz um curioso texto onde compara o estereoscópio ao telefone, intitulado Why Man has Used Pictures, and A Comparison Between the Telephone and the Stereoscope. Os textos de Ross: A Specimen Canvass and other help in the sale of Underwood e Underwood Stereographic Tours (1904), e The Underwood Travel System and How to Sell it (1905), em conjunto com o manual anônimo Manual of Instruction To be Studied and Followed by our Salesmen (UNDERWOOD \& UNDERWOOD, 1904), são textos de treinamento para os vendedores da companhia estereoscópica Underwood \& Underwood, e oferecem valiosa informação a respeito da apresentação e justificativas oferecidas aos clientes no momento da venda.

Manuais e literatura técnica

Os manuais de fotografia são de grande interesse. Tipicamente, são receituários e direções para a prática fotográfica, tanto amadora como profissional. Para a pesquisa estereoscópica, estes manuais podem servir de marcadores de difusão, ou seja, serviriam para sinalizar continuidades e incidências da prática estereoscópica do lado da produção fotográfica como um todo. Os manuais listados abaixo, embora pouco numerosos, parecem sugerir que há continuidade na difusão da prática estereoscópica, não apenas em publicações dedicadas exclusivamente a elas, como também em parte do corpus da prática fotográfica como um todo. Um veredicto de maior peso dependerá de um universo maior de publicações, mas julgamos útil compilar a lista parcial. De qualquer forma, parece seguro presumir que o conhecimento técnico estereoscópico esteve sempre presente, com maior ou menor destaque, na literatura da prática fotográfica, e que o estúdio fotográfico médio (até o início do século XX pelo menos) era capaz de oferecer o serviço se solicitado. $\bigcirc$ inventário de venda do estúdio de Militão de Azevedo, por exemplo, não menciona máquina fotográfica estereoscópica, mas por outro lado lista um lote de "109 cartões stereoscopicos" (Inventário, 31 de abril 1885), e há pelo menos uma estereoscopia certamente de sua autoria. Além disso, no manual Photographie in Amerique que Militão verteu para o português, encontramos um parágrafo apontando esta multiplicidade de modalidades (LIEBERT, 1878, p. 490), manuscrito que se encontra no Museu Paulista.

Um dado curioso que chama a atenção do pesquisador é a quaseausência de direções específicas para a composição estética de uma fotografia estereoscópica. Á única recomendação que se faz mais ou menos freqüentemente é a colocação de algum elemento no primeiro plano, à margem da fotografia, para destacar o efeito de profundidade. De outra forma, nenhuma sugestão de agrupamento de elementos - arranjo de cheios ou vazios - é mencionada. Por outro lado, um aspecto técnico importante encontra-se presente nos manuais como um todo: a inversão do negativo. Para que o efeito estereoscópico não degenerasse em pseudo-estereoscopia, a inversão das imagens no clichê fotográfico era obrigatória la imagem da lente esquerda deve ser vista pelo olho direito e viceversa) na revelação da fotografia diapositiva, quando as lentes da câmera fossem 
paralelas. Assim, o corte do negativo (particularmente sobre vidro) facilitou a dispersão de pares estereoscópicos ao longo do tempo. Ademais, outro aspecto importante é a tomada de pares estereoscópicos com uma só câmera, corrente ao longo, dos séculos XIX e XX ICOUSTET, [190?], p. 28; DAVANNE, 1886, p. 376; DISDÉRI, 1863, p. 29; TISSANDIER, 1874, p. 29; WESTELL, 1909, p. 17). Nessas condições, a câmera é deslocada para a segunda exposição - o retratado deve permanecer imóvel. Assim, não há coincidência necessária de formato entre aparato fotográfico e imagem estereoscópica resultante. De fato, a câmera usada na feitura do carte-de-visite podia também ser usada para a tomada de fotografia estereoscópica, como afirma o próprio Disdéri (1863, p. 29). A primeira câmera binocular foi provavelmente a francesa Quinetoscope, lançada em 1953 (GERNSHEIM, 1988, p. 69).

\section{REFERÊNCIAS}

BATCHEN, Geoffrey. Enslaved sovereign: on Jonathan Crary, techniques of the observer. Continuum:The Australian Journal of Media \& Culture, v.6,n.2,1991.Disponivel em:<http://wwwmcc.murdoch.edu.au/ ReadingRoom/6.2/Batchen.html)>.Download no site do Photogenic Papers.

BENJAMIN, W. The arcades project. Cambridge: Belknap Press of the Harvard University Press, 1999.

BETTI, U. Tratato teorico-pratico di fotografia. Livorno: Raffaello Giusti, 1878.

BREWSTER, David. The stereoscope; it's history, theory and construction. Hastings-on-Hudson, Nova York: Morgan \& Morgan, 1971. Edição fac-símile da edição da John Murray, Londres, 1856.

BRUNET, F. Le soleil peintre et sculpteur, avec un voyage stéréoscopique.Études photographiques, Paris, v. 9, p. 109-123, maio 2001.

BUCK-MORSS, Susan.Dialectics of seeing. Cambridge: MIT Press, 1990.

CHADWICK, William Isaac. How to make transparencies for lantern slides and stereoscopic slides. Manchester: Mowson \& Swan, 1890.

CÓRDOVA, Carlos A. Arqueologia de la imagen: México en las vistas estereoscópicas. Cidade do México: Museu de Historia Mexicana, [s.d.].

COSTA, Flavia Cesarino. O primeiro cinema: espetáculo, narração e domesticação.São Paulo: Escrita, 1995.

COUPÉ,A. Methode pratique porur l'obtention des diapositives. Paris: Gauthier-Villar, 1892.

COUSTET, E. La photographie stereoscopique en noir et en coloeurs. Paris: Mendel, [19-?].

CRARY,Jonathan. Techniques of the observer: on vision and modernity in the nineteenth century. Cambridge: MIT Press, 1990. 
CUNNINGHAM, D. J. The Edinburgh stereoscopic atlas of anatomy. Meadville: Keystone View, 1900.

DARRAH.,W.C.The world of stereographs. Nashville:Land Yatch Press, 1997. Disponível em:<http:/ /www.stereoview.org $>$. Disponível para compra do site da National Stereoscopic Association.

DAVANNE,A. La photographie. Paris: Gautier-Villars, 1886.

DAVIDSON, James MacKenzie. Localization by X-Rays. Londres: [s.n.], 1916.

DELESTRE, Jean-Baptiste. Traite de photographie. Paris: Desloges, 1857.

DEPARTMENT OFTHEARMY.Headquarters map reading. Washington:Exército Americano, 1960. (Field manual 21-26).

DISDÉRI. The Universal Textbook of Photograpy. Leeds: Harney, Reynolds \& Fowler, 1863.

L'art de la photographie. Paris:J. Claye, 1862.

DONNADIEU, A. L. Traité de photographie stereoscopique. Paris: Gauthier-Villars, 1892.

DROUIN, F. Le stereoscope. Bradford: Percy Lund, 1897.

DUBBINI, Renzo. Geography of the Gaze: urban and rural vision in early modern Europe. Chicago: University of Chicago Press, 2002.

EDER, J. M. History of photography. Nova York: Dover Publications, 1945.

FERREZ, Gilberto. A fotografia no Brasil: 1840-1900. Rio de Janeiro: Funarte/Pró-memória, 1985.

FERWERDA, J. G. The world of 3-D. Países Baixos: Netherlands Society, 1990.

FIGUIER, Louis. La photographie au salon de 1859 e la photographie Ele stereoscope. Nova York: Arno Press, 1979. Reedição de Paris: Hachette, 1860.

GERNSHEIM, Helmut. The rise of photography: 1850-1880. Londres:Thames \& Hudson, 1988.

GIOPPI,Luigi. La fotografia industriale: fotocalchi economici per le riproduzioni di disegni, piani. Milão: Hoepli, 1898.

GOSSER, H. Mark. Selected attempts at stereoscopic moving pictures and their relationship to the development of motion picture technology. Nova York:Arno Press, 1977.

GRAVY,Albert A. The labyrinth of animals, including mammals, birds, reptiles and amphibious. Londres:A Churchill, 1907.

HANKINS,Thomas L.;SILVERMAN, Robert J.Instruments and the imagination. Princeton: Princeton University Press, 1995. 
HOLMES, Oliver Wendell. Soundings from the Atlantic. Boston:Ticknor \& Fields, 1864.

INGLEBY, Clement Mansfield. The stereoscope considered on relation to the philosophy of binocular vision. Londres:Walton, 1853.

JAY, Martin. The denigration of vision in twentieth-century French thought. Berkeley: University of California Press, 1993.

JENKINS, H. F. Two points of view - the history of the parlor stereoscope. Nova York: World of Color, 1957.

JONES,T.Wharton. On the invention of stereoscopic glasses for single pictures and the physiology of stereoscopic vision. Londres: John Churchill, 1860.

JOUART,J.Abel.Application de la photographie aux levées militaires. Paris: J. Dumaine, 1866.

KEYSTONE. Thew world in the stereocope. Nova York: Hart and Anderson, 1872.

KOSSOY, Bóris. Dicionário bistórico de fotógrafos e do ofício fotográfico no Brasil (1840-1910). 2000. 5 v.Tese (Livre Docência) - São Paulo, 2000.

KRAUSS, Rosalind. The optical unconscious. Cambridge: MIT Press, 1994.

LARDNER, Dionisius (Ed.). The museum of science and art. Londres:Walton \& Maberly, 1856.v.X.

LEFEBVRE. Guide du peintre-coloriste, comprenout l'enluminage de gravures et lithographies, les coloris Daguerreotype, des vues sur verre pour Stereoscope. Paris: [s.n.], 1876-80.

LIEBERT,A. Photographie en Amerique. Paris:Tignol, 1878.

LONIE, William O. Prize essay on the stereoscope. Londres: London Stereoscopic, 1856.

MARDER,W.\& E. Anthony, the man the company, the cameras. Florida:Pine Ridge Publishing, 1982.

MOIGNO,F. N. M.Stereoscope; ses effets merveilleux. Pseudoscope; ses effets etranges. Paris: [s.n.], 1852.

MOITESSIER, A. La photographie appliquée aux recherches micrographiques. Paris: Bailliere, 1866.

MONCKHOVEN, D. A popular treatise on photography. Also, a description of, and remarks on, the stereoscope and photographic optics. Londres: Virtue Brothers, 1863. Disponível em: <http:// albumen.stanford.edu/library/monographs/monckh/>. Fac-símile disponível para download do site Albumen photographs: history, science and preservation.

NAZARIEFF, Serge. The stereoscopic nude: 1850-1930. Colônia:Taschen, 1993.

NEWHALL, Beaumont. History of photography. Nova York:The Museum of Modern Art, 1982.

ORVELL, Miles. The real thing: imitation and authenticity in american culture 1880-1940. Chapel Hill:The University of North Carolina Press, 1989. 
OSBORNE,Albert E. The stereograph and the stereoscope with special maps and books forming a travel system and what they mean for individual development, with their promise for the spread of civilization. Nova York: Underwood \& Underwood, 1909.

Why man has used pictures, and a comparison between the telephone and the stereoscope. Nova York: Underwood \& Underwood, 1904.

PARENTE,José Inácio.A estereoscopia no Brasil.Rio de Janeiro:Sextante/Dresdner Bank Brasil, 1999.

PERMUTT, C. Collecting photographic antiques. Wellingborough: PSL Patrick Stephens, 1986.

PESSANHA, Maria Edith de Araujo.A estereoscopia: o mundo em terceira dimensão. Rio de Janeiro: M. E.A. Pessanha, 1991.

PIAZZI-SMYTH, C. Tenerife, an astronomer's experiment. Londres: [s.n.], 1856.

RAYFIELD. Double dating: courtship ritual and the radical potential of stereographic viewing. Iconomania: studies in visual culture, 1998. Disponível em: $<$ http://www.humnet.ucla.edu/Icono/ IMhome.htm)> Disponível para download do site do Departamento de História da Arte da Universidade da California, Los Angeles.

REYNAUD, F.; TABRUN, C.; TIMBY, K. (Ed.). Paris in 3-D: from stereoscopy to virtual reality 18502000. Paris-Musées. Paris: Booth-Clibborn, 2000.

RICHARD,V.T.Norman McLaren, manipulator of movement. East Brunswick:Associated University Presses, 1982.

RICHARDSON, John. Double vision is but perfect vision, 1999. Disponível em: <http:// wwwmcc.murdoch.edu.au/ReadingRoom/stereo/pres/index.htm >. Disponível para download do Reading Room da Murdoch University.

RIO DE JANEIRO: 1862-1927: álbum fotográfico da formação da cidade Rio de Janeiro. Rio de Janeiro: IMS, 1998.

ROSS, E. R. A specimen canvass and other belp in the sale of Underwood \& Underwood stereographic tours. Londres: Underwood \& Underwood, 1904.

.The Underwood travel system and how to sell it. Londres:Underwood \& Underwood, 1905.

ROTHWELL, C. F. S. Elements of stereoscopic photography. Bradford: Percy Lund, 1896.

SALVESSEN, B. "The Most Magnificent, Useful and Interesting Souvenir": Representations of the International Exhibition of 1862. Visual Resources, v. XIII, p. 1-32, 1997.

SCHARF,Aaron. Art \& photography harmondsworth. Baltimore: Penguin, 1974.

SEIBERLING, G. Amateurs, photography and the mid-victorian imagination. Londres: The University of Chicago Press, 1986.

SMEE, Alfred.The eye in bealth and disease; with an account of the optometer, for the adaptation of glasses, for impaired, aged, or defective sight; being the substance of lectures delivered at the Central London ophthalmic bospital: to which is appended, a paper on the stereoscope and binocular perspective. $2^{\text {nd }}$. ed. Londres: Longman, 1854. 
SMITH,Lindsay. The Elusive Depth of Field:Stereoscopy and the Pre-Raphaelites. In:POINTON,Marcia (Ed.). Pre-raphaelites re-viewed. Manchester: Manchester University Press, 1989. p. 83-99.

SPOTISWOODE, Raymond; SPOTTISWOODE, Nigel. The theory of stereoscopic transmission. Berkeley: University of California Press, 1953.

STOLZE, DR.. F. Encyclopedie der photographie. [S.1.]: Halle A. S., 1894.

TISSANDIER, Gaston. Les merveilles de la photographie. Paris: Hachette, 1874.

TOWLER, J. The silver beam (fac-símile 1864). Nova York: Morgan \& Morgan, 1974.

TREADWELL,T. K.; DARRAH,W.C. Stereographers of the world. National Stereoscopic Association, 1994. Disponível em: <http://www.stereoview.org>. Disponível no site da National Stereoscopic Association.

TREADWELL,T. K. Facsimile reproductions of three articles by Oliver Wendell Holmes [Soundings from the Atlantic]. [S.1.]:The Institute for Photographic Research, 2000.

TURAZZI, Maria. Inez Poses e trejeitos: a fotografia e as exposições na era do espetáculo. Rio de Janeiro: Funarte/Rocco 1995.

.Artes do ofício:fotografia e memória da engenharia no século XIX. 1997.306.Tese (Doutorado)

- Faculdade de Arquitetura e Urbanismo, Universidade de São Paulo, São Paulo, 1997.

UNDERWOOD \& UNDERWOOD. Manual of instruction to be studied and followed by our salesmen. Londres: Underwood \& Underwood, 1904.

VASQUEZ,Pedro.Dom Pedro II e a fotografia no Brasil. Rio de Janeiro:Index/CIS/Roberto Marinho, 1988.

VIRILIO, Paul. War and cinema: the logistics of perception. Londres:Verso, 1989.

WADE, Nicholas. Brewster and Wheatstone on vision. Londres:Academic Press, 1983.

WESTELL, Perceval. Nature stalking for boys: through the field glass, stereoscope and camera. Londres: J. M. Dent, 1909.

WHEATSTONE, Charles. Contributions to the physiology of vision. Part the first. On some remarkable, and hitherto unobserved, phenomena of binocular vision, 1838. Disponível em: <http:/ /www.wehner.org/3d/first/p371.htm>. Fac símile.

WING, Paul. Stereoscopes: the first hundred years Nashua. New Hampshire:Transition Publishing, 1996. Disponível em: <http://www.stereoview.org > Disponível para compra no site da National Stereoscopic Association.

ZELLER, Bob. The civil war in depth: history in 3-D. São Francisco: Chronicle Books, 1997.

Artigo apresentado em 4/2003. Aprovado em 7/2003. 
Restauração da fotopintura em tamanho natural de Santos Dumont por Giovanni Sarracino

Yara Lígia Mello Moreira Petrella

Nazareth Coury

Sônia Maria Spigolon

Beatriz Carvalho Ricardo

Trata-se da apresentação dos procedimentos relativos à restauração da fotopintura em tamanho natural de Santos Dumont, feita pelo fotógrafo Giovanni Sarracino. Discute-se todas as fases que abragem desde o diagnóstico, critérios, definição de metodologias de recuperação até a reprodução e tratamento digitalizado da imagem.

PALAVRAS-CHAVE: Fotopintura. Conservação. Restauração digital.

Anais do Museu Paulista. São Paulo. N. Sér.v. 6/7.p. 161-180 (1998-1999). Editado em 2003.

Santos Dumont's natural-sized photo painting restoration by Giovanni Sarracino

Yara Lígia Mello Moreira Petrella

Nazareth Coury

Sônia Maria Spigolon

Beatriz Carvalho Ricardo

It is about the procedures concerning Santos Dumont's natural-sized photo painting restoration, made by the photographer Giovanni Sarracino. All the phases that comprehend from the diagnosis, criteria, definition and restoration methodologies to the reproduction and image-digitalized treatment are discussed.

KEYWORDS: Photo painting. Conservation. Digital Restoration.

Anais do Museu Paulista. São Paulo. N. Sér.v. 6/7. p. 161-180 (1998-1999). Editado em 2003.

Uma História da História da Fotografia

Ricardo Mendes

O ensaio aborda a constituição do campo da pesquisa sobre a fotografia no Brasil, com destaque para o segmento da história da fotografia a partir da década de 1970. A análise procura identificar os principais agentes (pesquisadores, entidades e programas institucionais) e detectar suas interações segundo uma primeira proposta de periodização sobre o tema.

PALAVRAS-CHAVE: Fotografia. História da fotografia. Fotografia brasileira. Historiografia

Anais do Museu Paulista. São Paulo. N. Sér.v. 6/7. p. 183-205 (1998-1999). Editado em 2003.

A story of the History of Photography

Ricardo Mendes

The essay examines the constitution of Brazil's photography research field, with prominence to the segment of History of Photography, starting from the decade of 1970. The analysis tries to identify the main agents (researchers, entities and institutional programs) and detect their interactions according to a first periodization proposal on the subject.

KEYWORDS: Photography, History of Photography, Brazilian Photography, historiography. Anais do Museu Paulista. São Paulo. N. Sér.v. 6/7.p. 183-205 (1998-1999). Editado em 2003

Um balanço bibliográfico e de fontes da estereoscopia

\section{Gavin Adams}

O balanço bibliográfico que se segue é uma reflexão acerca da organização de títulos que tratam da estereoscopia. Menos do que uma tentativa de listar todos os títulos disponíveis em uma bibliografia completa, a presente reflexão quer mapear os tipos principais de publicação de interesse estereoscópico encontrados no curso de sua pesquisa de doutorado. Ademais, o presente balanço quer oferecer uma meditação sobre algumas das particularidades e incidências da bibliografia encontrada, de modo a oferecer ao pesquisador da estereoscopia um guia inicial para seus trabalhos. 
PALAVRAS-CHAVE: Estereoscopia. Bibliografia.Visualidade.

Anais do Museu Paulista. São Paulo. N. Sér. v. 6/7.p. 207-225 (1998-1999). Editado em 2003.

A bibliographic and stereoscopy sources balance

\section{Gavin Adams}

The bibliographic balance that follows is a reflection on the organization of titles about stereoscopy. Less than an attempt to compile a complete list of all available titles into a complete bibliography, the present reflection aims to map the main kinds of publication of stereoscopic interest found by the author in the course of his PhD research. In addition, the present balance aims to ponder on some of the particularities and incidences of such bibliography, so as to offer the researcher on stereoscopy an initial guide to his or her work.

KEYWORDS: Stereoscopy. Bibliography.Visuality.

Anais do Museu Paulista. São Paulo. N. Sér. v. 6/7. p. 207-225 (1998-1999). Editado em 2003 